\title{
Socioeconomic inequalities of outpatient and inpatient service utilization in China: personal and regional perspectives
}

\author{
Dawei Zhu' ${ }^{1}$ Na Guo², Jian Wang ${ }^{3}$, Stephen Nicholas ${ }^{4,5,6,7}$ and Li Chen ${ }^{1,8^{*}}$
}

\begin{abstract}
Background: China's health system has shown remarkable progress in health provision and health outcomes in recent decades, however inequality in health care utilization persists and poses a serious social problem. While government pro-poor health policies addressed affordability as the major obstacle to equality in health care access, this policy direction deserves further examination. Our study examines the issue of health care inequalities in China, analyzing both regional and individual socioeconomic factors associated with the inequality, and provides evidence to improve governmental health policies.

Methods: The China Health and Nutrition Survey (CHNS) 1991-2011 data were used to analyze the inequality of health care utilization. The random effects logistic regression technique was used to model health care utilization as the dependent variable, and income and regional location as the independent variables, controlling for individuals' age, gender, marital status, education, health insurance, body mass index (BMI), and period variations. The dynamic trend of 1991-2011 regional disparities was estimated using an interaction term between the regional group dummy and the wave dummy.
\end{abstract}

Results: The probability of using outpatient service and inpatient services during the previous 4 weeks was 8.6 and $1.1 \%$ respectively. Compared to urban residents, suburban (OR: 0.802, 95\% Cl: $0.720-0.893$ ), town (OR: $0.722,95 \%$ Cl: $0.648-0.804$ ), rich (OR: $0.728,95 \%$ Cl: $0.656-0.807)$ and poor village (OR: $0.778,95 \%$ $\mathrm{Cl}$ : 0.698-0.868) residents were less likely to use outpatient service; and rich (OR: 0.609, 95\% Cl: 0.472-0.785) and poor village (OR: $0.752,95 \%$ Cl: $0.576-0.983$ ) residents were less likely to use inpatient health care. But the differences between income groups were not significant, except the differences between top and bottom income group in outpatient service use.

Conclusion: Regional location was a more important factor than individual characteristics in determining access to health care. Besides demand-side subsidies, Chinese policy makers should pay enhanced attention to health care resource allocation to address inequity in health care access.

Keywords: Health care utilization, Inequality, Resource allocation, Health policy

\footnotetext{
* Correspondence: lichen1@augusta.edu

${ }^{1}$ Center for Health Policy and Management, Institute of Medical Information

\& Library, Chinese Academy of Medical Sciences \& Peking Union Medical

College, Beijing 100020, China

${ }^{8}$ Georgia Prevention Institute, Department of Population Health Sciences,

Medical College of Georgia, Augusta University, Augusta 30912, GA, USA

Full list of author information is available at the end of the article
} 


\section{Background}

Since the 1978 reform and opening up period, China has experienced enormous demographic and socioeconomic changes. China's gross domestic product (GDP) per capita increased from \$US1145 in 2000 to \$US8016 in 2015 [1], and China has also made remarkable progress in the development of its health care system. For example, practicing (assistant) physicians per thousand population grew from 1.68 in 2000 to 2.12 in 2014 and the life expectancy of the Chinese population increased by 4 years [2]. However, rapid growth and longevity has brought increased income inequality, with the individual income Gini coefficient rising from 0.401 in 2000 to 0.462 in 2015. Mirroring China's income inequalities, the gap between the rich and the poor in access to health care has also widened. There is strong evidence of pro-rich inequality in China health system $[3,4]$. By 2014, the average yearly health care expenditure was \$US189.05 among urban residents, but only \$US109.22 among rural residents. Of course, inequality of health care utilization is not unique to China, but also exits in many other developing $[5,6]$ and developed countries [7-10]. Studies conducted in a number of developed and developing countries also found that rich residents have a higher probability of obtaining health care when sick than the poor. Therefore, improving health care equity and closing the gap between the rich and poor in accessing health care have become priorities for health systems in many countries and organizations [11-13].

Equal access to qualified health care has two major components, affordability and availability [14]. Affordability and availability of health care services are two sides of the same coin when seen from the individual and regional perspectives. Affordability of health care, mainly related to household income, health insurance reimbursement rates and other income-related factors, has received the most attention in assessing health systems and improving their performance. The availability of health care describes access from the regional level, which is linked mainly to health care resource allocations, governmental funding and government policies.

Different causes of inequity should be tackled with different corresponding compensation strategies. Enhancing the affordability mostly refers to demand-side financing strategies such as pro-poor subsidies and insurance for low-income residents schemes [15]. But regional factors that compromise the availability of health care services should be corrected with supply-side compensation, like grants for health care infrastructure and salary subsidies for health workers. In recent years, demand-side subsidies have been extensively applied to address health care access. Researchers and policy makers argue that demand-side financing is not only better at targeting subsidies to the poor, but by linking subsidies with output, they also provide the right incentives for efficiency $[16,17]$. Supply-side financing strategies have been criticized for their inefficiencies [16, 18].

Recent research has resulted in some unexpected findings that are incompatible with the above supply-side versus demand-side intuitions concerning inequalities. There is no unanimity in the research on health care equality that shows that affordability is a more important cause of (in)equality of service utilization than availability. Feng et al. found that regional factors were more significant indicators of hospital births in China than individual income [19] and Li et al. showed that urbanrural and core-periphery gaps were significant determinants in health care access in Henan province [20]. Van Doorslaer et al. found no evidence of income-related inequity in GP visits in European countries [8] and M.Makinen et al. found that in developing countries, the richer households did not devote a consistently higher percentage of their consumption expenditures to health care [5].

Without careful examination, demand and supply-side intuitions concerning health care inequalities can result in misguided policy-making. Health care financing strategies employed in China and other countries require careful analysis. This study analyzes the personal and regional socioeconomic factors associated with inequalities in health care utilization in China and provides evidence and recommendations for improving governmental health policy financing.

\section{Methods}

\section{Data sources}

Data were obtained from the China Health and Nutrition Survey (CHNS), which utilizes a multistage, random cluster sampling strategy to collect longitudinal data across 228 communities within 9 provinces of China. A detailed description of the survey design and procedures are available in Zhang B et al. [21]. We accessed eight waves of CHNS surveys conducted between 1991 and 2011, with the final sample comprising 73,110 observations after excluding observations with missing data.

\section{Measures/variables}

The main objective of this study is to compare the impact of individual factors and regional factors on the inequality of health care utilization. The dependent variable measured whether a resident utilized outpatient or inpatient services during the past 4 weeks, and the two key independent variables were the individual's personal income quintile and the region of residence. Sampled individuals were divided into five income groups, according to their income quintile (top to bottom), and sampled communities were divided into five 
regional categories, comprising urban, suburban, town, rich village and poor village. Rich versus poor villages were categorized by their per capita income. Following Andersen's behavioral model of health care utilization, comprising predisposing characteristics (such as demographics, and position within the social structure), enabling characteristics (such as economic status), and need based characteristics (perception of need for health services) [22], we controlled for age, gender, marital status, education level, health insurance and body mass index (BMI). Although self-report health status (SRH) is a widely used proxy variable for health needs [23-25], SRH did not appear in all of the CHNS questionnaires. Since BMI is associated with SRH [26], health-related quality of life [27, 28] and mortality risk [29], BMI was used to proxy health status. In addition, wave dummies for each of 8 collection points between 1991 and 2011 were added into the model to capture the period effects. Table 1 presents definitions for all variables in the analysis.

\section{Statistical analysis}

Data analysis was performed by using the STATA 14.0 (College Station, Texas USA) and carried out by descriptive statistics and the random-effects logit model.

Descriptive statistics for utilizing outpatient and inpatient service were reported as counts and proportions, with corresponding chi-square and the $p$-values, to examine whether there were statistically significant differences between subgroups. Second, we adopted the random effects logit model using panel data to investigate regional disparities. Panel data models can offset potential problems associated with unobserved heterogeneity that may induce inconsistent estimators in crosssectional models. To get consistent and efficient estimators, panel data analysis involves both fixed effects models and the random-effects models. Some variables in our models do not vary over time, such as gender, occupation, and regional groups, which would be omitted in fixed effects models. Since these variables are important factors explaining healthcare utilization, randomeffects models were employed to retain those variables in our model.

The model was specified as:

$$
\ln \left(\frac{P_{i t}}{1-P_{i t}}\right)=\beta_{0}+\beta_{1} R G_{i t}+\beta_{2} I G_{i t}+\sum_{k=1}^{K} \alpha_{k} x_{k i t}+\mu_{i}
$$

where $P_{i t}$ represented the probability of utilization of outpatient and inpatient service of individual $i$ at period $t$; $R G_{i t}$ indicated region group; $I G_{i t}$ represented the income group; $\beta_{0}$ was the intercept; coefficients $\beta_{1}$ and $\beta_{2}$ represented region disparities and income disparities. Further, $x_{k i t}$ were control variables, such as age, gender, marital status, education level and so on, where $\alpha_{k}$ is $k$ th regression coefficient; $\mu_{i}$ was the random effect representing the effect of the $i$ individual. In addition to exploring the dynamic trend of regional disparities from 1991 to 2011, an interaction term between regional group dummies and wave dummies was added into the model.

\section{Results}

Table 2 displays the descriptive statistics for the variables in the entire sample as well as the outpatient and inpatient samples. During the previous 4 weeks, the probability of using outpatient service was $8.6 \%$ and using inpatient services was $1.1 \%$. Table 2 shows that over the period 1991-2011, the probability of using outpatient services and inpatient service utilization first declined and then increased. The probability of using outpatient and inpatient services were significantly $(p<0.001)$ different across regional groups. Urban residents had the highest outpatient and inpatient service utilization, while individuals who lived in rich villages had the lowest probability. The results in Table 2 show that the rate of clinic visits was significantly $(p<0.001)$ different across income groups. The bottom-income group was more likely to use the outpatient service, while the middleincome group was less likely to be outpatients. But, the rates of hospitalization did not vary significantly by income groups. The results also indicated that outpatient and inpatient service utilization were significantly different across all the control variables, except gender.

Figures 1 and 2 shown outpatient and inpatient service use among income and regional groups between 1991 and 2011. As shown in the Fig. 1, the disparity in the outpatient rate between income groups was very small before 2004, reaching a minimum in 2000, but increased after 2004. The disparity in the outpatient rate between regional groups decreased before 2006, then began to widen. The two figures demonstrate that the disparity of inpatient use was larger than outpatient use, and the disparity between regional groups was larger than between income groups in most years.

Results of the random effects regressions for income and regional disparities in health care utilization are presented in Table 3, with region and income groups highlighted. As showed in the first column, after controlling for confounding variables, suburban (odds ratio $(\mathrm{OR})=0.802$, 95\% confidence interval (CI): 0.720-0.893), town (OR: 0.722, 95\% CI: 0.648-0.804), rich (OR: 0.728, 95\% CI: $0.656-0.807$ ) and poor village (OR: $0.778,95 \%$ CI: $0.698-0.868)$ residents were less likely to use outpatient services, but the differences between income groups were not significant, except the differences between top and bottom income group in outpatient service use (OR: 1.134, 95\% CI: 1.021-1.258). The results also show that outpatient service utilization was more 
Table 1 Variable definitions

\begin{tabular}{|c|c|}
\hline Variable & Variable definitions \\
\hline \multicolumn{2}{|l|}{ Wave } \\
\hline 1991 & Reference group \\
\hline 1993 & 1 if survey conducted at 1993; 0 otherwise \\
\hline 1997 & 1 if survey conducted at 1997; 0 otherwise \\
\hline 2000 & 1 if survey conducted at 2000; 0 otherwise \\
\hline 2004 & 1 if survey conducted at 2004; 0 otherwise \\
\hline 2006 & 1 if survey conducted at 2006; 0 otherwise \\
\hline 2009 & 1 if survey conducted at 2009; 0 otherwise \\
\hline 2011 & 1 if survey conducted at $2011 ; 0$ otherwise \\
\hline \multicolumn{2}{|l|}{ Region group } \\
\hline Urban & Reference group \\
\hline Suburban & $\begin{array}{l}1 \text { if respondents lived in suburban; } \\
0 \text { otherwise }\end{array}$ \\
\hline Town & 1 if respondents lived in town; 0 otherwise \\
\hline Rich village & $\begin{array}{l}1 \text { if respondents lived in rich village; } \\
0 \text { otherwise }\end{array}$ \\
\hline Poor village & $\begin{array}{l}1 \text { if respondents lived in poor village; } \\
0 \text { otherwise }\end{array}$ \\
\hline \multicolumn{2}{|l|}{ Income group } \\
\hline Quintile1 & Reference group \\
\hline Quintile2 & $\begin{array}{l}1 \text { if in the second highest quintile; } \\
0 \text { otherwise }\end{array}$ \\
\hline Quintile3 & $\begin{array}{l}1 \text { if income in the middle quintile; } \\
0 \text { otherwise }\end{array}$ \\
\hline Quintile4 & $\begin{array}{l}1 \text { if income in the second lowest quintile; } \\
0 \text { otherwise }\end{array}$ \\
\hline Quintile5 & $\begin{array}{l}1 \text { if income in the bottom quintile; } \\
0 \text { otherwise }\end{array}$ \\
\hline \multicolumn{2}{|l|}{ Age group } \\
\hline $0 \sim$ & Reference group \\
\hline $16 \sim$ & 1 if aged $16-30 ; 0$ otherwise \\
\hline $31 \sim$ & 1 if aged $31-45 ; 0$ otherwise \\
\hline $46 \sim$ & 1 if aged $46-60 ; 0$ otherwise \\
\hline $61 \sim$ & 1 if older than 60; 0 otherwise \\
\hline \multicolumn{2}{|l|}{ Gender } \\
\hline Male & Reference group \\
\hline Female & 1 if female; 0 otherwise \\
\hline \multicolumn{2}{|l|}{ Marriage status } \\
\hline Never married & Reference group \\
\hline Married & 1 if married; 0 otherwise \\
\hline Others & $\begin{array}{l}1 \text { if divorced, widowed, separated, } \\
\text { or unknow; } 0 \text { otherwise }\end{array}$ \\
\hline \multicolumn{2}{|l|}{ Education level } \\
\hline Below primary school & Reference group \\
\hline Grad from primary & 1 if grad from primary; 0 otherwise \\
\hline Junior middle school & $\begin{array}{l}1 \text { if grad from junior middle school; } \\
0 \text { otherwise }\end{array}$ \\
\hline $\begin{array}{l}\text { Senior middle school } \\
\text { or above }\end{array}$ & $\begin{array}{l}1 \text { if grad from senior middle school } \\
\text { or above; } 0 \text { otherwise }\end{array}$ \\
\hline
\end{tabular}

Table 1 Variable definitions (Continued)

\begin{tabular}{ll}
\hline Variable & Variable definitions \\
\hline Health insurance & Reference group \\
No & 1 if no insurance; 0 otherwise \\
BMl & \\
Underweight & Reference group \\
Normal weight & 1 if $18.5<=\mathrm{BMl}<26 ; 0$ otherwise \\
Overweight & 1 if $26<=\mathrm{BMI}<31 ; 0$ otherwise \\
Obese & 1 if $\mathrm{BMI}>=31 ; 0$ otherwise \\
\hline
\end{tabular}

likely to occur for those in old age, female and married groups, and was less likely to occur for those with high education levels and from the high BMI group. For inpatient use (column 3 in Table 3), significant differences were observed for rich (OR: 0.609, 95\% CI: 0.472-0.785) and poor village residents (OR: 0.752, 95\% CI: 0. 5760.983), but there was no significant difference between income groups. Older age and health insurance increased the probability of hospitalization. When we excluded regional groups in model 2 (columns 2 and 4), the results remained roughly the same. Our results show that the inequalities in healthcare utilization were fundamentally caused by regional, not personal income, disparities.

Table 4 and Fig. 3 present the dynamic trends of regional disparities in health utilization from 1991 to 2011. The rate of outpatient utilization increased before 2004, and then declined. In urban areas, the rate of increase was much greater than other regions before 2004, and the decline more rapidly from 2004 to 2009 . The rate of inpatient health care utilization presented a fluctuating decreasing trend. The rate of decrease was much less in the urban region and much greater in rich villages.

\section{Discussion}

Compared to urban residents, we found suburban, town, rich and poor village residents were less likely to use outpatient services; and rich and poor village residents were less likely to use inpatient health care. Differences between income groups were not significant, except the differences between top and bottom income group in outpatient service use. In the random effects logit models with wave-region interactions, we found that China was making progress in increasing health care resource allocation and improving accessibility. Although the gap between urban and rural regions was closing, the disparity among regions remained significant.

Largely consistent with existing studies, the major determinants of inequality of health care utilization in our study were age, gender, BMI, education, marriage status and health insurance, where the last three were not need-related factors. Elwell-Sutton found these non- 
Table 2 Descriptive statistics

\begin{tabular}{|c|c|c|c|c|c|}
\hline \multirow[t]{2}{*}{ Characteristics } & \multirow{2}{*}{$\begin{array}{l}\text { Sample } \\
\mathrm{N}(\%)^{\mathrm{a}}\end{array}$} & \multicolumn{2}{|l|}{ Outpatient } & \multicolumn{2}{|l|}{ Inpatient } \\
\hline & & $\overline{N(\%)^{b}}$ & $P$ & $\overline{N(\%)^{b}}$ & $P$ \\
\hline Wave & & & $<0.001$ & & $<0.001$ \\
\hline 1991 & $9976(13.7)$ & $656(6.6)$ & & $158(1.6)$ & \\
\hline 1993 & $9139(12.5)$ & $272(3.0)$ & & $78(0.9)$ & \\
\hline 1997 & $9304(12.7)$ & $427(4.6)$ & & $61(0.7)$ & \\
\hline 2000 & $9226(12.6)$ & $464(5.0)$ & & $43(0.5)$ & \\
\hline 2004 & $8023(11.0)$ & $964(12.0)$ & & $78(1.0)$ & \\
\hline 2006 & 7908(10.8) & $897(11.3)$ & & $74(0.9)$ & \\
\hline 2009 & 8396(11.5) & 1011(12.0) & & $106(1.3)$ & \\
\hline 2011 & $11,138(15.2)$ & $1602(14.4)$ & & $186(1.7)$ & \\
\hline Region group & & & $<0.001$ & & $<0.001$ \\
\hline Urban & $11,777(16.1)$ & 1331(11.3) & & $195(1.7)$ & \\
\hline Suburban & $12,919(17.7)$ & $1082(8.4)$ & & $142(1.1)$ & \\
\hline Town & $11,734(16.1)$ & $941(8.0)$ & & $155(1.3)$ & \\
\hline Rich village & $18,225(24.9)$ & 1376(7.6) & & $134(0.7)$ & \\
\hline Poor village & $18,455(25.2)$ & 1563(8.5) & & $158(0.9)$ & \\
\hline Income group & & & 0.002 & & 0.111 \\
\hline Quintile1 & $14,620(20.0)$ & $1268(8.7)$ & & $176(1.2)$ & \\
\hline Quintile2 & $14,622(20.0)$ & $1210(8.3)$ & & $167(1.1)$ & \\
\hline Quintile3 & $14,616(20.0)$ & $1204(8.2)$ & & $163(1.1)$ & \\
\hline Quintile4 & $14,629(20.0)$ & $1237(8.5)$ & & $142(1.0)$ & \\
\hline Quintile5 & $14,623(20.0)$ & 1374(9.4) & & $136(0.9)$ & \\
\hline Age group & & & $<0.001$ & & $<0.001$ \\
\hline $0 \sim$ & 7015(9.6) & $210(3.0)$ & & $27(0.4)$ & \\
\hline $16 \sim$ & $13,303(18.2)$ & $510(3.8)$ & & $62(0.5)$ & \\
\hline $31 \sim$ & $20,597(28.2)$ & $1229(6.1)$ & & $168(0.8)$ & \\
\hline $46 \sim$ & $19,374(26.5)$ & 2108(10.9) & & $207(1.1)$ & \\
\hline $60 \sim$ & $12,821(17.5)$ & $2236(17.4)$ & & $320(2.5)$ & \\
\hline Gender & & & $<0.001$ & & 0.741 \\
\hline Male & $35,212(48.2)$ & $2704(7.7)$ & & $373(1.1)$ & \\
\hline Female & $37,898(51.8)$ & $3589(9.5)$ & & $411(1.1)$ & \\
\hline Marriage status & & & $<0.001$ & & $<0.001$ \\
\hline Never married & $14,697(20.1)$ & $477(3.3)$ & & $62(0.4)$ & \\
\hline Married & $53,401(73.0)$ & $5037(9.4)$ & & $615(1.2)$ & \\
\hline Others & $5012(6.9)$ & $779(15.5)$ & & 107(2.1) & \\
\hline Education level & & & $<0.001$ & & $<0.001$ \\
\hline $\begin{array}{l}\text { Below primary } \\
\text { school }\end{array}$ & $19,829(27.1)$ & 2185(11.0) & & $280(1.4)$ & \\
\hline Grad from primary & $15,950(21.8)$ & $1361(8.5)$ & & $162(1.0)$ & \\
\hline Junior middle school & $21,723(29.7)$ & $1489(6.9)$ & & $184(0.9)$ & \\
\hline $\begin{array}{l}\text { Senior middle } \\
\text { school or above }\end{array}$ & $15,608(21.4)$ & $1258(8.1)$ & & $158(1.0)$ & \\
\hline Health insurance & & & $<0.001$ & & $<0.001$ \\
\hline Yes & $39,239(53.7)$ & $2433(6.2)$ & & $248(0.6)$ & \\
\hline No & $33,871(46.3)$ & $3860(11.4)$ & & $536(1.6)$ & \\
\hline
\end{tabular}

Table 2 Descriptive statistics (Continued)

\begin{tabular}{|c|c|c|c|c|c|}
\hline \multirow[t]{2}{*}{ Characteristics } & \multirow{2}{*}{$\begin{array}{l}\text { Sample } \\
\mathrm{N}(\%)^{\mathrm{a}}\end{array}$} & \multicolumn{2}{|l|}{ Outpatient } & \multicolumn{2}{|l|}{ Inpatient } \\
\hline & & $\overline{N(\%)^{b}}$ & $P$ & $\overline{N(\%)^{b}}$ & $P$ \\
\hline $\mathrm{BMI}$ & & & $<0.001$ & & $<0.001$ \\
\hline Underweight & $10,385(14.2)$ & $701(6.8)$ & & $78(0.8)$ & \\
\hline Normal weight & $51,797(70.85)$ & $4243(8.2)$ & & $547(1.1)$ & \\
\hline Overweight & $9692(13.26)$ & $1153(11.9)$ & & $142(1.5)$ & \\
\hline Obese & $1236(1.69)$ & 196(15.9) & & $17(1.4)$ & \\
\hline Over all & $73,110(100.0)$ & $6293(8.6)$ & & $784(1.1)$ & \\
\hline
\end{tabular}

${ }^{a}$ Sample distribution among each character

${ }^{\mathrm{b}}$ Number and percentage of health care utilization

need related factors made the largest pro-rich contributions to health case use [30]. However, our results show that income was not as prominent a factor in health care inequality as in previous studies [4, 30]. While health status proxies health need, and self-report health status (SRH) is a widely used proxy variable for health need [23-25], SRH did not appeared in all of the CHNS questionnaires. CHNS provided consistent data on BMI, and BMI is associated with SRH [26], health-related quality of life [19, 31-34] and mortality risk [29]. Used as a proxy variable of health status, we found BMI had a significant association with outpatient utilization.

Regional factors had a more important impact on health care utilization than individual income. That inequality between socioeconomic regions is more pronounced than between individuals is also true in other countries [19, 31-34]. Van Doorslaer et al. found that location of residence contributed to the inequality of health service utilization in Europe and the US [35]. Brezzi et al. also showed that in addition to individual factors, the characteristics of the region where people live, such as the average skill endowment or employment rate, had a significant impact on the probability of unmet medical needs in selected OECD countries [33]. Devaux illustrated that the utilization of cancer screening services largely depended on the availability of national public screening programs, which varied by region across selected OECD countries [10]. In common with Chinese regional health inequalities [36], regional inequality also occurs in national development [37], economic growth [38], income levels [39] and education [40].

Health care accessibility in remote rural regions lags behind urban regions for several reasons. First, practicing (assistant) physicians per thousand population in rural countries (1.51) were less than half of those in urban cities (3.54) in 2014 [1]. A similar pattern can also be observed in the urban-rural allocation of nurses. Second, geographical factors also contribute to the availability of health care. Zhang et al. found that residents whose houses' were more than $5 \mathrm{~km}$ from the nearest health facilities were less likely to utilize health care 


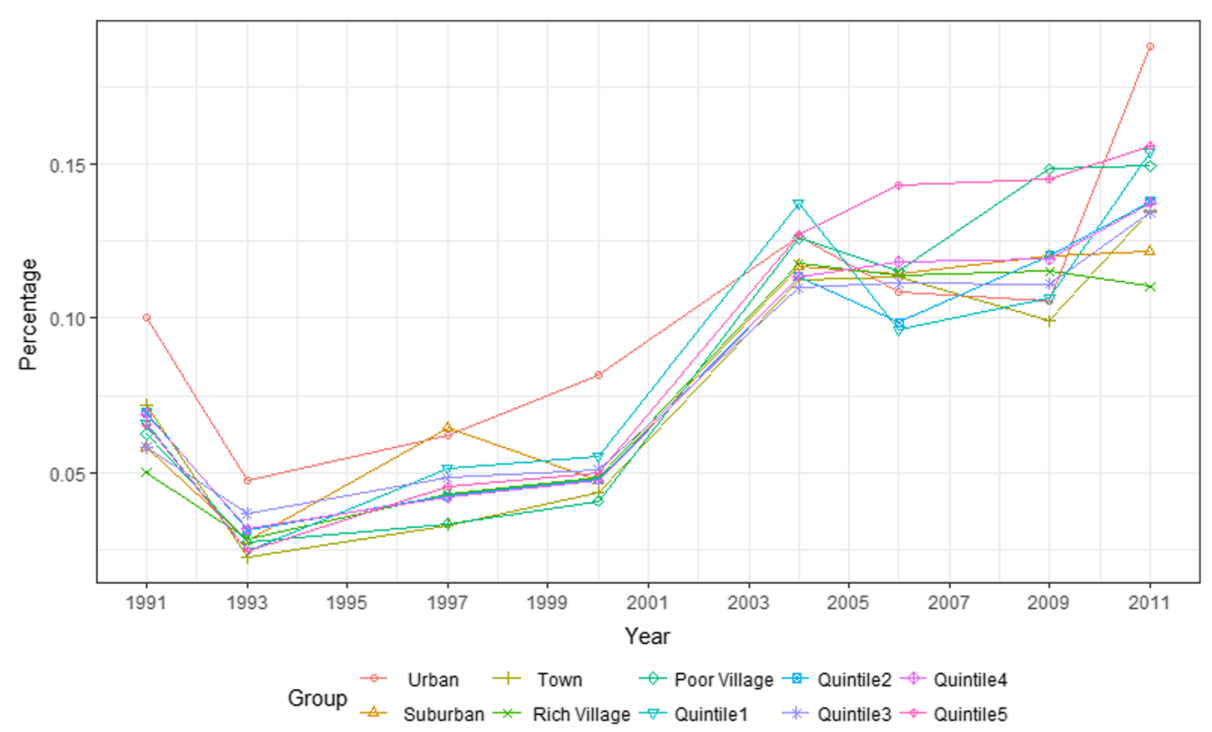

Fig. 1 Outpatient service use among income and regional groups in China (1991-2011)

services than those whose house was less than $5 \mathrm{~km}$ from health facilities [4]. Third, government financial support is highly dependent on the local economy. The central government only contributes a limited share of the financial inputs into health care facilities, so rich provinces invest more in health than poorer provinces. Finally, the uneven quality and accessibility to social resources impacts on health care quality.Social resources including education, public transport and commerce, are vital factors that attract human resource and funding [41]. Health care disparity is one of the demonstrated consequences of socioeconomic inequality [36].
Two turning points were identified in our trend analysis. From 1993 to 1997, disparity of inpatient health care utilizations among regions dramatically increased, with only urban areas displaying an increasing utilization trend, while other regions, especially villages, decreased rapidly (see Fig. 3). In China's health care reform history, commercialization of public health care was encouraged by the $14^{\text {th }}$ Central Committee of the Chinese Communist Party held in 1992 [42], including profit making, diversification of services and cost recovery. As shown in our results, the commercialization side effects were apparent with increasing inequality in access when health care facilities closed down or were sold to private

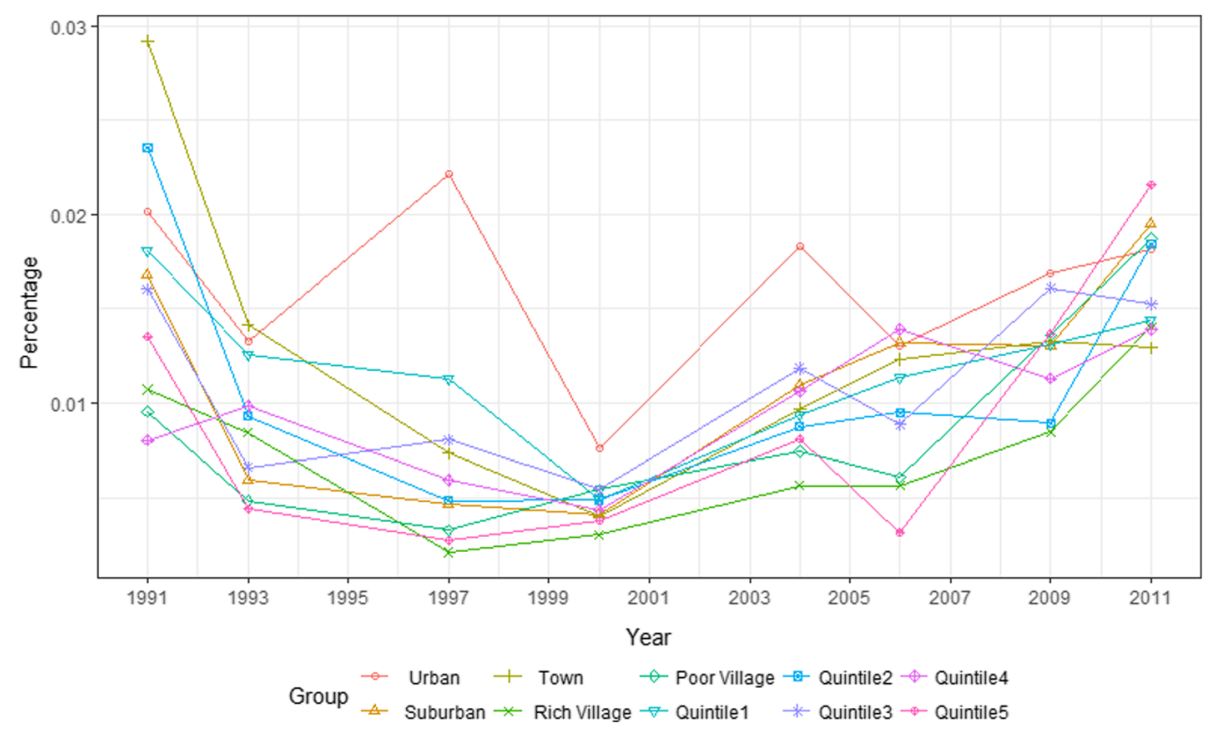

Fig. 2 Inpatient service use among income and regional groups in China (1991-2011) 
Table 3 Regression results of random effects logit ${ }^{a}$

\begin{tabular}{|c|c|c|c|c|}
\hline & \multicolumn{2}{|l|}{ Outpatient } & \multicolumn{2}{|l|}{ Inpatient } \\
\hline & Model 1 & Model 2 & Model 1 & Model 2 \\
\hline Intercept & $0.032(0.004)^{* * *}$ & $0.025(0.003)^{* * *}$ & $0.004(0.001)^{* *}$ & $0.003(0.001)^{* * *}$ \\
\hline \multicolumn{5}{|l|}{ Region group } \\
\hline Urban & Reference & & Reference & \\
\hline Suburban & $0.802(0.044)^{* * * *}$ & & $0.899(0.112)$ & \\
\hline Town & $0.722(0.040)^{* * *}$ & & $0.939(0.113)$ & \\
\hline Rich village & $0.728(0.038)^{* * * *}$ & & $0.609(0.079)^{* * *}$ & \\
\hline Poor village & $0.778(0.043)^{* * * *}$ & & $0.752(0.103)^{* *}$ & \\
\hline \multicolumn{5}{|l|}{ Income group } \\
\hline Quintile1 & Reference & Reference & Reference & Reference \\
\hline Quintile2 & $1.003(0.048)$ & $0.985(0.047)$ & $1.069(0.123)$ & $1.052(0.121)$ \\
\hline Quintile3 & $1.035(0.051)$ & $0.995(0.049)$ & $1.213(0.146)$ & $1.158(0.137)$ \\
\hline Quintile4 & $1.064(0.055)$ & $1.022(0.051)$ & $1.118(0.145)$ & $1.056(0.133)$ \\
\hline Quintile5 & $1.134(0.060)^{* *}$ & $1.091(0.055)^{*}$ & $1.072(0.148)$ & $1.017(0.132)$ \\
\hline \multicolumn{5}{|l|}{ Age group } \\
\hline $0 \sim$ & Reference & Reference & Reference & Reference \\
\hline $16 \sim$ & $1.065(0.115)$ & $1.050(0.113)$ & $1.098(0.311)$ & $1.066(0.302)$ \\
\hline $31 \sim$ & $1.280(0.154)^{* *}$ & $1.278(0.154)^{* *}$ & $1.721(0.544)^{*}$ & $1.704(0.539)^{*}$ \\
\hline $46 \sim$ & $2.149(0.259)^{* * *}$ & $2.183(0.262)^{* * * *}$ & $2.156(0.682)^{* *}$ & $2.181(0.690)^{* *}$ \\
\hline $60 \sim$ & $3.431(0.416)^{* * *}$ & $3.580(0.433)^{* * *}$ & $4.704(1.482)^{* * *}$ & $5.014(1.578)^{* * *}$ \\
\hline \multicolumn{5}{|l|}{ Gender } \\
\hline Male & Reference & Reference & Reference & Reference \\
\hline Female & $1.171(0.040)^{* * *}$ & $1.185(0.040)^{* * *}$ & $0.992(0.080)$ & $1.011(0.082)$ \\
\hline \multicolumn{5}{|l|}{ Marriage status } \\
\hline Never married & Reference & Reference & Reference & Reference \\
\hline Married & $1.453(0.118)^{* * *}$ & $1.430(0.116)^{* * *}$ & $1.255(0.269)$ & $1.239(0.266)$ \\
\hline Others & $1.480(0.143)^{* * *}$ & $1.471(0.142)^{* * *}$ & $1.445(0.354)$ & $1.451(0.356)$ \\
\hline \multicolumn{5}{|l|}{ Education level } \\
\hline Below primary school & Reference & Reference & Reference & Reference \\
\hline Grad from primary & $0.924(0.042)^{*}$ & $0.932(0.042)$ & $0.982(0.109)$ & $0.994(0.110)$ \\
\hline Junior middle school & $0.775(0.038)^{* * *}$ & $0.801(0.038)^{* * *}$ & $0.865(0.102)$ & $0.914(0.107)$ \\
\hline Senior middle school or above & $0.767(0.043)^{* * *}$ & $0.835(0.044)^{* * *}$ & $0.795(0.106)^{*}$ & $0.913(0.117)$ \\
\hline Health insurance & $1.273(0.051)^{* * * *}$ & $1.299(0.052)^{* * *}$ & $2.213(0.224)^{* * *}$ & $2.336(0.234)^{* * *}$ \\
\hline \multicolumn{5}{|l|}{ BMl } \\
\hline Underweight & Reference & Reference & Reference & Reference \\
\hline Normal weight & $0.710(0.040)^{* * *}$ & $0.711(0.040)^{* * *}$ & $0.985(0.142)$ & $1.001(0.144)$ \\
\hline Overweight & $0.835(0.056)^{* * *}$ & $0.839(0.056)^{* * *}$ & $1.127(0.188)$ & $1.169(0.196)$ \\
\hline Obese & $1.067(0.116)$ & $1.064(0.115)$ & $0.988(0.291)$ & $1.029(0.303)$ \\
\hline
\end{tabular}

${ }^{* * *} p<0.01 ;{ }^{* *} p<0.05 ;{ }^{*} p<0.1$

${ }^{a}$ Cells represent odds ratio (standard error). Categorical variable wave indicating year of survey was included in the model, not shown in the table

individuals in rural areas. Medical costs rapidly increased and co-operative medicine collapsed. The second turning point was 2006, where the gap among regions started to close. The main contributor of this trend was the establishment of the New Cooperative Medical Scheme
(NCMS). In 2003, NCMS was implemented in rural areas, with about half of the rural counties having roughly a $80 \%$ NCMS enrollment rate by June 2006 [43] and $97.5 \%$ enrolment rate by 2011 [44]. Pre-NCMS, about $80 \%$ of the rural residents was not covered by any 
Table 4 Adjusted trends in health care utilization by regional groups, 1991-2011ª

\begin{tabular}{|c|c|c|c|c|c|c|c|c|}
\hline Region & ref. & 1993 & 1997 & 2000 & 2004 & 2006 & 2009 & 2011 \\
\hline \multicolumn{9}{|l|}{ Clinic Visit } \\
\hline Urban & 0 & $-0.587(0.151)^{* * *}$ & $-0.244(0.129)^{*}$ & $0.014(0.120)$ & $0.425(0.107)^{* * *}$ & $0.195(0.116)^{*}$ & $0.097(0.115)$ & $0.847(0.080)^{* * *}$ \\
\hline Suburban & 0 & $-0.900(0.166)^{* * *}$ & $-0.012(0.113)$ & $-0.397(0.128)^{* * *}$ & $0.490(0.099)^{* * *}$ & $0.384(0.101)^{* * *}$ & $0.288(0.101)^{* * *}$ & $0.244(0.097)^{* *}$ \\
\hline Town & 0 & $-1.259(0.190)^{* * *}$ & $-0.840(0.165)^{* * *}$ & $-0.503(0.142)^{* * *}$ & $0.347(0.111)^{* * *}$ & $0.327(0.108)^{* * *}$ & $0.067(0.113)$ & $0.400(0.092)^{* * *}$ \\
\hline Rich village & 0 & $-0.822(0.132)^{* * *}$ & $-0.455(0.114)^{* * *}$ & $-0.373(0.111)^{* * *}$ & $0.492(0.090)^{* * *}$ & $0.344(0.091)^{* * *}$ & $0.211(0.091)^{* *}$ & $0.092(0.090)$ \\
\hline Poor village & 0 & $-0.906(0.134)^{* * *}$ & $-0.759(0.125)^{* * *}$ & $-0.548(0.118)^{* * *}$ & $0.533(0.088)^{* * *}$ & $0.256(0.091)^{* * *}$ & $0.449(0.087)^{* * *}$ & $0.361(0.086)^{* * *}$ \\
\hline \multicolumn{9}{|l|}{ Inpatient } \\
\hline Urban & 0 & $-0.669(0.277)^{* *}$ & $-0.042(0.216)$ & $-1.229(0.339)^{* * *}$ & $-0.450(0.243)^{*}$ & $-0.898(0.289)^{* * *}$ & $-0.795(0.254)^{* * *}$ & $-0.698(0.189)^{* * *}$ \\
\hline Suburban & 0 & $-1.055(0.351)^{* * * *}$ & $-1.237(0.370)^{* * *}$ & $-1.447(0.394)^{* * *}$ & $-0.666(0.268)^{* *}$ & $-0.621(0.251)^{* *}$ & $-0.991(0.254)^{* * *}$ & $-0.633(0.210)^{* * *}$ \\
\hline Town & 0 & $-0.301(0.249)$ & $-0.953(0.339)^{* * *}$ & $-1.557(0.426)^{* * *}$ & $-0.971(0.315)^{* * *}$ & $-0.791(0.279)^{* * *}$ & $-1.012(0.268)^{* * *}$ & $-1.062(0.235)^{* * *}$ \\
\hline Rich village & 0 & $-0.410(0.241)^{*}$ & $-2.006(0.459)^{* * *}$ & $-1.666(0.392)^{* * *}$ & $-1.315(0.321)^{* * *}$ & $-1.678(0.323)^{* * *}$ & $-1.505(0.263)^{* * *}$ & $-1.040(0.211)^{* * *}$ \\
\hline Poor village & 0 & $-0.885(0.310)^{* * *}$ & $-1.429(0.370)^{* * *}$ & $-0.864(0.299)^{* * *}$ & $-0.898(0.283)^{* * *}$ & $-1.475(0.311)^{* * *}$ & $-1.069(0.224)^{* * *}$ & $-0.784(0.198)^{* * *}$ \\
\hline
\end{tabular}

${ }^{a}$ Cells represent coefficient (standard error)

${ }^{*} p<0.1 ;{ }^{* *} p<0.05 ;{ }^{* * *} p<0.01$

form of health insurance [43]. As the results of our study suggest, NCMS significantly improved health care access in rural areas.

Besides demand-side subsidies, policy makers should pay more attention to the equity of health care resource allocation. Governments have mainly focused on explicit pro-poor health policies to correct the inequality of health care by enhancing the affordability of access to health care, such as targeted health sector subsidies for the poor [45] and community-based health insurance [46]. Although health insurance is a key factor in promoting health facility access, our study showed that the gap between high and low-income individuals was nearly closed and income factors lost their significance after adjusting for other impact factors. There are some existing supply-side schemes in China. The most important one is governmental financial reimbursement of capital construction and equipment purchase. However, barriers imped their implementation. First, a variety of pro-poor demand-side subsidies co-exist within four ministries (Health, Social Security, Civil Affairs and Finance), but only two ministries (Health and Finance) are responsible for supply-side subsidies. Second, the amounts of financial inputs into supply-side schemes are usually highly related to local government revenue, which means differential health care spending between rich and poor local governments will see health care gaps between regions perpetuated.

Our findings emphasize supply-side inequality in health care utilization. While income-related inequalities

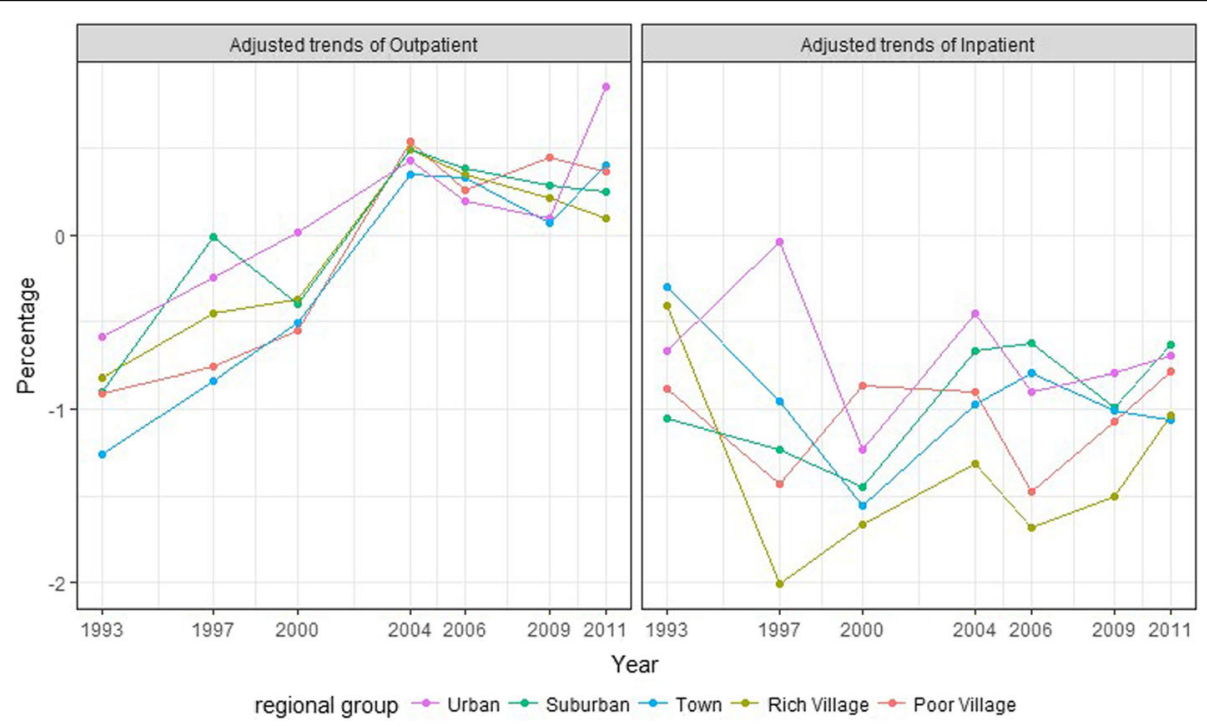

Fig. 3 Adjusted trends of health care utilization by regional groups, 1991-2011 
contributed to access to health care facilities, the importance of regional disparities in health care access has been underestimated. We recommend monitoring supply-side factors in health policies. Based on our findings, more hospitals, clinics, physicians and nurses should be allocated to remote rural areas to tackle health care facility availability. If availability is the key bar to health care access, then additional funding to enhance affordability will not significantly improve health care access. China's 1992 health care reforms that 'marketized' hospitals provides a lesson that reminds us how availability affects the health care utilization, regardless of the affordability.

This study has the following limitations. Relying on secondary data, some measures of the dimensions of access to health care, such as affordability, and some potential confounding factors, are missing. Second, all data were based on self-reporting, which might lead to recall and information bias. Thirdly, these data are collected before 2012. External validity is nuanced since health care reform strategies are evolving and new regulations have been launched during the last several years. Lastly, as restricted by secondary data, health care utilization based on need and demand cannot be easily divided, so the results should be interpreted with care.

\section{Conclusion}

We found that regional factors were a more important determinant of inequalities of health care utilization than individual, especially income, factors. Second, availability of services was a more prominent issue in China than affordability. While being cognizant of issues of demand-side subsidies, policy makers should pay increased attention to inequalities in health care utilization arising from resource allocation issues.

\begin{abstract}
Acknowledgements
This research uses data from China Health and Nutrition Survey (CHNS). We thank the National Institute for Nutrition and Health, China Center for Disease Control and Prevention, Carolina Population Center (P2C HD050924, T32 HD007168), the University of North Carolina at Chapel Hill, the NIH (R01-HD30880, DK056350, R24 HD050924, and R01-HD38700) and the NIH Fogarty International Center (D43 TW009077, D43 TW007709) for financial support for the CHNS data collection and analysis files from 1989 to 2015 and future surveys, and the China-Japan Friendship Hospital, Ministry of Health for support for CHNS 2009, Chinese National Human Genome Center at Shanghai since 2009, and Beijing Municipal Center for Disease Prevention and Control since 2011.
\end{abstract}

\section{Funding}

This work was supported by the National Natural Science Foundation of China (grant number 71503267 and 71702131) and Ministry of Education in China Project of Humanities and Social Sciences (grant number 15YJC630009).

\section{Availability of data and materials}

The datasets analyzed during the current study are available in the China Health and Nutrition Survey (CHNS) repository, http://www.cpc.unc.edu/ projects/china.

\section{Authors' contributions}

LC participated in the design of the study, performed the statistical analysis and drafted the manuscript. NG contributed to conduct the study, collect research data, and figures and paper preparation. JW participated in the interpretation of data and revised the paper. SN drafted and revised the manuscript. DZ participated in the design of the study and statistical analysis. All authors read and approved the final manuscript.

\section{Ethics approval and consent to participate}

This research has been approved by the Institutional Review committees of the University of North Carolina at Chapel Hill and the National Institute for Nutrition and Health, Chinese Center for Disease Control and Prevention. All participants gave written informed consent for their participation in the survey.

\section{Consent for publication}

Not applicable.

\section{Competing interests}

The authors declare that they have no competing interests. The funders had no role in study design, data collection, data analysis or writing of the report.

\section{Publisher's Note}

Springer Nature remains neutral with regard to jurisdictional claims in published maps and institutional affiliations.

\section{Author details}

${ }^{1}$ Center for Health Policy and Management, Institute of Medical Information \& Library, Chinese Academy of Medical Sciences \& Peking Union Medical College, Beijing 100020, China. ${ }^{2}$ China Population and Development Research Center, Beijing 100081, China. ${ }^{3}$ School of Public Health, Shandong University, Jinan 265400, China. ${ }^{4}$ School of Management and School of Economics, Tianjin Normal University, Tianjin 300074, China. ${ }^{5}$ Guangdong Research Institute of International Strategies, Guangdong University of Foreign Studies, Guangzhou 510420, China. ${ }^{6}$ Beijing Foreign Studies University, Beijing 100089, China. ${ }^{7}$ Newcastle Business School, University of Newcastle, Newcastle 2308, NSW, Australia. ${ }^{8}$ Georgia Prevention Institute, Department of Population Health Sciences, Medical College of Georgia, Augusta University, Augusta 30912, GA, USA.

Received: 13 August 2017 Accepted: 23 November 2017

Published online: 04 December 2017

\section{References}

1. PRC NBoS. China statistical yearbook 2016 (Chinese-English edition). Beijing: China Statistics Press; 2016

2. Programme UND: Human development report 2015: work for human development. 2015.

3. Yang W, Jian W, Maitland E, Zhao Y, Nicholas S, Lu M. Growing old before growing rich: inequality in health service utilization among the mid-aged and elderly in Gansu and Zhejiang provinces, China. BMC Health Serv Res. 2012:12(1):1-11.

4. Zhang X, Wu Q, Shao Y, Fu W, Liu G, Coyte PC. Socioeconomic inequities in health care utilization in China. Asia Pac J Public Health. 2015;27(4):429-38.

5. Makinen $M$, Waters $H$, Rauch $M$, Almagambetova $N$, Bitran $R$, Gilson L, Mcintyre D, Pannarunothai S, Prieto AL, Ubilla G. Inequalities in health care use and expenditures: empirical data from eight developing countries and countries in transition. Bull World Health Organ. 2000;78(1):55-65.

6. Dorjdagva J, Batbaatar E, Dorjsuren B, Kauhanen J. Income-related inequalities in health care utilization in Mongolia, 2007/2008-2012. Int J Equity Health. 2015;14(1):1-10.

7. Kroll LE, Lampert T. Direct costs of inequalities in health care utilization in Germany 1994 to 2009: a top-down projection. BMC Health Serv Res. 2013; 13(1):1-9.

8. Van DE, Koolman X, Jones AM. Explaining income-related inequalities in doctor utilisation in Europe. Health Econ. 2004;13(7):629-47.

9. Sözmen $\mathrm{K}$, Ünal B. Explaining inequalities in health care utilization among Turkish adults: findings from health survey 2008. Health Policy. 2016;120(1): 100-10.

10. Devaux M. Income-related inequalities and inequities in health care services utilisation in 18 selected OECD countries. Eur J Health Econ. 2015;16(1):21-33. 
11. Murray CJ, Frenk J. A framework for assessing the performance of health systems. Bull World Health Organ. 2000;78(6):717-31.

12. Kelley E, Hurst J. Health care quality indicators project. Oecd. 2006;

13. Cheung PTY. China's changing regional development: trends, strategies and challenges in the 12th five-year plan (2011-2015) period. Asia Pacific Viewpoint. 2012;53(1):1-6.

14. Kruk ME, Freedman LP. Assessing health system performance in developing countries: a review of the literature. Health Policy. 2008;85(3):263-76.

15. Tuppin P, Drouin J, Mazza M, Weill A, Ricordeau P, Allemand H. Hospitalization admission rates for low-income subjects with full health insurance coverage in France. Eur J Pub Health. 2011;21(5):560-6.

16. Bhatia MR, Thankappan KR. Demand side financing for reproductive and child health Services in India. Economic \& Political Weekly. 2006;41(3):279-84.

17. Van Hoofstat R. Demand side subsidies can boost supply in a more efficient way. Housing Finance International. 2012;

18. Gopalan SS, Mutasa R, Friedman J, Das A. Health sector demand-side financial incentives in low- and middle-income countries: a systematic review on demand- and supply-side effects. Soc Sci Med. 2014;100(1):72-83.

19. Feng $X \mathrm{~L}, \mathrm{Xu} \mathrm{L}$, Guo Y, Ronsmans $\mathrm{C}$. Socioeconomic inequalities in hospital births in China between 1988 and 2008. Bulletin of the World Health Organisation. 2011:89(6):432-41.

20. Li Y, Wei YD. Multidimensional inequalities in health care distribution in provincial China: a case study of Henan Province. Tijdschr Econ Soc Geogr. 2014;105(1):91-106.

21. Zhang B, Zhai FY, Du SF, Popkin BM. The China health and nutrition survey, 1989-2011. Obes Rev. 2014;15(Suppl 1):2-7.

22. Andersen RM. Revisiting the behavioral model and access to medical care: does it matter? J Health Soc Behav. 1995;36(1):1-10.

23. Benjamins MR, Hummer RA, Eberstein IW, Nam CB. Self-reported health and adult mortality risk: an analysis of cause-specific mortality. Soc Sci Med. 2004;59(6):1297-306

24. Idler EL, Angel RJ. Self-rated health and mortality in the NHANES-I epidemiologic follow-up study. Am J Public Health. 1990;80(4):446-52.

25. Wu SQ, Wang R, Zhao YF, Ma XQ, Wu MJ, Yan XY, He J. The relationship between self-rated health and objective health status: a population-based study. BMC Public Health. 2013:13:320.

26. Krijger K, Schoofs J, Marchal Y, Van de Vijver E, Borgermans L, Devroey D. Association of objective health factors with self-reported health. J Prev Med Hyg. 2014;55(3):101-7.

27. Tarride JE, Haq M, Taylor VH, Sharma AM, Nakhai-Pour HR, O'Reilly D, Xie F, Dolovich L, Goeree R. Health status, hospitalizations, day procedures, and physician costs associated with body mass index (BMI) levels in Ontario, Canada. Clinicoecon Outcomes Res. 2012;4:21-30.

28. Garcia-Mendizabal MJ, Carrasco JM, Perez-Gomez B, Aragones N, GuallerCastillon P, Rodriguez-Artalejo F, Lopez-Abente G, Pollan M. Role of educational level in the relationship between body mass index (BMI) and health-related quality of life (HRQL) among rural Spanish women. BMC Public Health. 2009;9:120.

29. Nuttall FQ. Body mass index: obesity, BMI, and health: a critical review. Nutr Today. 2015;50(3):117-28

30. Elwell-Sutton TM, Chao QJ, Wei SZ, Cheng KK, Tai HL, Leung GM, Schooling CM. Inequality and inequity in access to health care and treatment for chronic conditions in China: the Guangzhou biobank cohort study. Health Policy Plan. 2013;28(5):467-79.

31. Wennberg JE: Regional inequality in Medicare spending: the key to Medicare reform? : Forum for Health Economics \& Policy. Forum Health Econ Policy 2010, 3(1):1017-1017.

32. Colais P, Agabiti N, Fusco D, Pinnarelli L, Sorge C, Perucci CA, Davoli M. Inequality in 30-day mortality and the wait for surgery after hip fracture: the impact of the regional health care evaluation program in Lazio (Italy). Int J Qual Health Care. 2013;25(3):239-47.

33. Brezzi $M$, Luongo P. Regional disparities in access to health care: a multilevel analysis in selected OECD countries. Oecd Regional Development Working Papers. 2016;

34. Sharma A: Socio-economic and regional inequalities in utilization of maternal health Care in Uttar Pradesh, India. 2016

35. Van Doorslaer E, Wagstaff A, van der Burg H, Christiansen T, De Graeve D, Duchesne I, Gerdtham U, Gerfin M, Geurts J, Gross L. Equity in the delivery of health Care in Europe and US. J Health Econ. 2000;19(5):553-83.

36. Li Y, Wei YHD. A spatial-temporal analysis of health care and mortality inequalities in China. Social Science Electronic Publishing. 2010;51(6):767-87.
37. Williamson J. Regional inequality and the process of national development. Econ Dev Cult Chang. 1965;17(4):89-97.

38. Tirado DA, Díez-Minguela A, Martinez-Galarraga J. Regional inequality and economic development in Spain, 1860-2010. J Hist Geogr. 2016;54:87-98.

39. Anthony M. Night lights and regional income inequality in Africa. Working Paper. 2015;

40. Kang H, Dai Z, Ma X, Bao X, Lin S, Ma H, Liu X, Wang X. Regional inequality and primary education in northern Uganda. Development. 2007;12(4):163-6.

41. Keidel A. Chinese regional inequalities in income and well-being. Rev Income Wealth. 2009;55(s1):538-61.

42. Wong VC, Chiu SW. Health-care reforms in the People's Republic of Chinastrategies and social implications. J Manag Med. 1998;12(4-5):270-86. 197

43. Wang H, Gu D, Dupre ME. Factors associated with enrollment, satisfaction, and sustainability of the new cooperative medical scheme program in six study areas in rural Beijing. Health Policy. 2008:85(1):32-44.

44. Hou Z, Van de Poel E, Van Doorslaer E, Yu B, Meng Q. Effects of NCMS on access to care and financial protection in China. Health Econ. 2014;23(8):917-34.

45. Ir P. Using targeted subsidies to improve access to health care for the poor in low-income countries: lessons from Cambodia 2000-2009. Vrije Universiteit Brussel Faculteit Geneeskunde En Farmacie:2011.

46. Souares A, Savadogo G, Dong H, Parmar D, Sié A, Sauerborn R. Using community wealth ranking to identify the poor for subsidies: a case study of community-based health insurance in Nouna, Burkina Faso. Health Soc Care Commun. 2011;18(4):363-8.

\section{Submit your next manuscript to BioMed Central and we will help you at every step:}

- We accept pre-submission inquiries

- Our selector tool helps you to find the most relevant journal

- We provide round the clock customer support

- Convenient online submission

- Thorough peer review

- Inclusion in PubMed and all major indexing services

- Maximum visibility for your research

Submit your manuscript at www.biomedcentral.com/submit
) Biomed Central 